\title{
PERCEPÇÕES SOBRE MEIO AMBIENTE E O MAR POR INTERESSADOS EM ECOTURISMO MARINHO NA ÁREA DE PROTEÇÃO AMBIENTAL MARINHA DE ARMAÇÃO DE BÚZIOS, ESTADO DO RIO DE JANEIRO, RJ, BRASIL
}

\author{
Alexandre Gusmão Pedrini ${ }^{1}$ \\ Daniel Shimada Brotto ${ }^{2}$ \\ Marcela Coronel Lopes ${ }^{3}$ \\ Luisa Pegrucci Ferreira ${ }^{4}$ \\ Natalia Pirani Ghilardi-Lopes ${ }^{5}$
}

Resumo: É imperativa a avaliação de concepções ambientais previamente à proposição de ações de educação ambiental. Neste trabalho, 78 questionários foram preenchidos por interessados em ecoturismo em Armação de Búzios, a respeito de seus conceitos sobre meio ambiente e meio ambiente marinho. Os respondentes apresentaram, em sua maioria, idades entre 41 e 50 anos, nível superior e renda de 1 a 4 salários mínimos. Aqueles originários da Região dos Lagos apresentaram o conceito integrador com frequência significativamente mais baixa (Qui-quadrado, $\chi^{2}=8,73, p<0,5 \%$ ) que os demais. Não foi observada diferença significativa $\left(\chi^{2}=0,811, p>5 \%\right)$ para a concepção de meio ambiente entre os sexos. Verificou-se que a maioria dos respondentes $(61 \%)$ não soube conceituar apropriadamente o ambiente marinho. Foram observadas diferenças significativas $(\mathrm{p}<5 \%$ ) quanto à origem e sexo dos respondentes para este conceito. É urgente a implantação de programas de informação e Educação Ambiental, direcionados a todos os segmentos sociais locais.

Palavras-Chave: Unidade de conservação marinha. Percepção ambiental. Ambiente marinho.

\section{ENVIROMENTAL PERCEPTIONS BY ECOTOURISM DEALEARS AND COSTUMERS IN THE MARINE PROTECTED AREA OF ARMAÇÃO DE BÚZIOS, STATE OF RIO DE JANEIRO, RJ, BRAZIL}

\footnotetext{
1 Doutor em Ciência da Informação, professor associado do Instituto de Biologia Roberto Alcântara Gomes da Universidade do Estado do Rio de Janeiro(UERJ), Rio de Janeiro, Rio de Janeiro, Brasil, pedrini@globo.com.

2 Doutor em Ciências Ambientais, professor adjunto da Universidade Veiga de Almeida (UVA), Rio de Janeiro, Riode Janeiro, Brasil, danshima@ig.com.br.

3 Graduanda em Oceanografia, Faculdade de Oceanografia da Universidade do Estado do Rio de Janeiro (UERJ), Rio de Janeiro, Rio de Janeiro, Brasil, cella_coronellopes@ig.com.br.

${ }^{4}$ Graduanda em Oceanografia, Faculdade de Oceanografia da Universidade do Estado do Rio de Janeiro (UERJ), Rio de Janeiro, Rio de Janeiro, Brasil ,luizalpf@gmail.com.

${ }^{5}$ Doutora em Botânica, professora adjunta do Centro de Ciências Naturais e Humanas da Universidade Federal do ABC (UFABC), São Paulo, Brasil, natalia.lopes@ufabc.edu.br.
} 
Abstract: The evaluation of environmental conceptions is imperative before any proposition of environmental education activities. In this study, 78 people fulfilled a questionnaire regarding their conceptions about environment and marine environment. They were in majority between 41 to 50 years old, with higher education and of 1-4 minimum wage income. Those from Lagos Region presented the integrative conception of environment with a significant higher frequency (Chi-square, $\chi^{2}=8,73, \mathrm{p}<0,5 \%$ ) than the others. No significant difference $\left(\chi^{2}=0,811, p>5 \%\right)$ was observed for the conception of environment when gender was considered. The majority $(61 \%)$ did not know how to appropriately onceptualize the marine environment. Significant differences $(p<5 \%)$ were observed regarding the origin and gender of the respondents for this concept. There is an urgent need for the implementation of Environmental Education and Information programs in the region, directed towards all local social segments.

Keywords: Marine protected areas. Environmental perception. Marine environment.

\section{PERCEPCIONES SOBRE EL MEDIO AMBIENTE Y EL MAR POR INTERESADOS EN ECOTURISMO MARINO EN EL ÁREA DE PROTECCIÓN AMBIENTAL MARINA DE ARMAÇÃO DE BÚZIOS, ESTADO DE RIO DE JANEIRO, RJ, BRASIL}

Resumen: Es imperativa la evaluación previa de las concepciones ambientales a la propuesta de acciones de educación ambiental. En este trabajo, interesados en ecoturismo rellenaron 78 cuestionarios en Armação de Búzios, a respecto de sus conceptos sobre medio ambiente y medio ambiente marino. Los encuestados presentaron, en su mayoría, edades entre 41 y 50 años, nivel superior y renta de 1 a 4 salarios mínimos. Aquellos originarios de la Región de los Lagos presentaron el concepto integrador con frecuencia significativamente más baja (Qui-cuadrado, $\chi^{2}=8,73, p<0,5 \%$ ) que los demás. No se observó diferencia significativa $\left(\chi^{2}=0,811, p>5 \%\right)$ para la concepción de medio ambiente entre los sexos. Se verificó que la mayoría de los encuestados (61\%) no supo conceptuar apropiadamente el ambiente marino. Se observaron diferencias significativas $(p<5 \%)$ en cuanto al origen y sexo de los encuestados para este concepto. Es urgente la implantación de programas de información y Educación Ambiental, direccionados a todos los segmentos sociales locales.

Palabras Clave: Unidad de conservación marina. Percepción ambiental. Ambiente marino.

\section{Introdução}

Muitas vezes, a legislação socioambiental de cada país, por si só, não assegura que os ideais de sustentabilidade se concretizem de forma satisfatória e rápida. $\mathrm{Na}$ verdade, os poucos avanços em direção a uma sociedade sustentável vem sendo obtidos com enormes dificuldades e 
poucas vitórias. Tem-se percebido que os avanços ou retrocessos dependem, em grande parte, do nível educacional e da consciência das questões socioambientais, além da vontade de resolver os conflitos gerados pelas diferentes concepções de uso do espaço territorial.

No Brasil, e em outros países que também possuem vasto patrimônio socioambiental, apenas contemporaneamente se percebe que os limites toleráveis de impactos em ecossistemas marinhos e costeiros já foram há algum tempo atingidos, em face da expansão da ocupação e do manejo utilitarista desses ecossistemas e dos seus integrantes pela nossa sociedade. Essa exacerbada e contínua invasão e a consequente extinção de habitats, espécies e comunidades da biodiversidade marinha nem sempre são evitadas por medidas como a fiscalização e a aplicação de multas (MMA, 2010). Assim sendo, aliada à fiscalização, à aplicação de multas e à detenção dos praticantes de crimes ambientais é fundamental que a educação ambiental (EA) seja desenvolvida.

A Educação Ambiental no contexto marinho está, ainda, nos seus primórdios no Brasil, sendo implementada apenas a partir dos anos 2000 (BERCHEZ; CARVALHAL; ROBIM, 2005; PRATES et al. 2007; VASCONCELOS; AMARAL; STEINER, 2008; HADEL, 2010). Acrescenta-se que o turismo do modo como é realizado tem trazido mais malefícios que benefícios (SALES; ANTONIO FILHO, 2008). Há trabalhos que mostram o efeito negativo do turismo na costa brasileira; em alguns casos, mesmo dentro de Unidades de Conservação (UC's) (BERCHEZ; CARVALHAL; ROBIM, 2005; BERCHEZ et al., 2007; SILVA; GHILARDILOPES, 2012), sendo que, muitas vezes, há de fato uma deseducação ambiental. Assim sendo, podemos hipotetizar que os turistas possuam concepções equivocadas, inadequadas sobre o que significa meio ambiente e ambiente marinho, ou que tais concepções estejam ausentes, pelo que se evidencia de sua visitação às UC's. Dessa forma, justifica-se a importância da análise das percepções relativas aos principais construtos básicos, por eles trazidas, de forma que se possa embasar a criação e a realização de atividades de Educação Ambiental e/ou de ecoturismo no contexto marinho. Objetiva-se, neste trabalho, a avaliação dos conceitos de meio ambiente e ambiente marinho de atores sociais envolvidos com Armação de Búzios. É importante que esses conceitos sejam conhecidos para a realização do verdadeiro ecoturismo marinho (GARROD; WILSON; BRUCE, 2002).

\section{Referencial Teórico}

\subsection{Percepção ambiental}

A análise de Percepção Ambiental (PA) possui variadas possibilidades de adoção em diversificados contextos (PACHECO; SILVA, 2006). Sua importância tem sido, essencialmente, como ferramenta diagnóstica tanto para questões humanas como ambientais. A PA vem sendo estudada por meio de várias abordagens metodológicas que, na realidade, buscam identificar a percepção cognitiva da temática ambiental, que, se espera, seja reflexo do cotidiano da pessoa pesquisada. Whyte (1977), no contexto do Programa Homem e Biosfera, da UNESCO, fez relevante síntese dos métodos adotados em pesquisas de campo. Apresentou, ainda, os benefícios dessa estratégia metodológica e sintetizou as técnicas e modelos para se realizar adequadamente pesquisas em PA. A autora destacou a importância do estudo da PA como forma de identificar problemas e encaminhar possibilidades de soluções concretas de questões práticas socioambientais, partindo das concepções de cada pessoa e de sua coletividade.

A PA é um construto conceitual complexo (TUAN, 1980; MARIN; OLIVEIRA; COMAR, 2003; ALVES, 2010). A análise de PA tem sido adotada, contemporaneamente, em variados contextos como poderosa ferramenta de identificação dos conceitos e entendimentos que as pessoas possuem sobre determinado fenômeno ou questão. Estudos de PA sempre devem 
preceder as ações de EA, pois colaboram no diagnóstico do contexto que poderá ser alvo de suas ações (PEDRINI; ANDRADE-COSTA; GHILARDI, 2010a). Nesse caso, é relevante considerar os preceitos de Marin, Oliveira e Comar (2003) que mostraram que a percepção na busca da apreensão da realidade não pode ser apenas pelas vias racionalistas, embasadas somente em características conceituais. Há sempre o risco de se apreender uma visão simplista do fenômeno perceptivo, que poderá levar o investigador a uma compreensão reducionista do que se pesquisa. Deve-se estar atento a essa possibilidade real.

Segundo Smythe (1995) a percepção que temos sobre o meio externo pode ser mudada pelo ambiente interno do perceptor, que identifica o meio em função das demandas do observador. Então, tanto o meio interno como o externo influenciam-se mutuamente, todo o tempo. Os resultados obtidos na análise de percepção ambiental, via de regra, são identificados como representações sociais dos sujeitos estudados (REIGOTA, 2007). Reigota (2007) analisou as representações sociais sobre meio ambiente de professores de ensino médio de regiões brasileiras, propondo uma tipologia baseada nas representações sociais de Moscovici (2007). Reigota entende que as representações sociais formam um conjunto de princípios elaborados interativamente. Esses são compartilhados por diversificados grupos sociais que, através delas, entendem e buscam transformar sua realidade. Concluindo, para se identificar as representações sociais de meio ambiente, devem ser conhecidas as percepções dos sujeitos. Assim, se podem desconstruir os equívocos e se reconstruir concepções de meio ambiente identificadas.

\subsection{Meio Ambiente}

O conceito de Meio Ambiente tem recebido inúmeras definições. Segundo Guimarães (2004) as pessoas e o meio ambiente encontram-se fundidos permanentemente. Nessa fusão se dá a percepção e a interpretação, as quais são processos que se desenvolvem a partir das sensibilidades e concretudes do meio exterior (objetivo) e interior (subjetivo), além da geração de símbolos e imagens, sentimentos e expressões, determinam relações de territorialidades, identidades e alteridades originais. Para cada nova vivência, o meio ambiente passa a ser percebido através de renovadas leituras, traduzindo significados diferentes nas dimensões espaçotemporal e cultural, trazendo à luz uma identidade especial, única, uma visibilidade firmada mediante imagens de paisagens fortemente arraigadas, importantes no conjunto dos significados das reações vivenciais, tornando-se ícones das realidades objetiva (manifestada) e subjetiva (manifestante).

O conceito de Meio Ambiente mais usado como referencial teórico é o de Reigota (2007), que o classifica em três categorias: a) Naturalista/Naturalizante: meio ambiente como sinônimo de natureza intocada, caracterizando-se tipicamente pelos aspectos naturais; b) Antropocêntrico/Humanizante: meio como fonte dos recursos naturais para a sobrevivência do ser humano; c) Globalizante/Integrador: meio integrado pela natureza e sociedade. Essa tipologia, embora bastante simples, tem sido muito adotada no Brasil por ser de fácil aplicação e interpretação. Também é adotada no presente estudo.

\subsection{Ambiente Marinho}

No Brasil, o conceito de mar ou ambiente marinho tem sido pouco estudado pela ótica da percepção ambiental. Em geral, o mar tem sido essencialmente percebido pela humanidade sob uma perspectiva utilitarista (TOMMASI, 2008; SOUZA et al., 2008). Souza et al. (2008), trabalhando com pessoas do estado nordestino do Maranhão, confirmam essa visão: alimentação $(80 \%)$, transporte $(46 \%)$, lazer $(45 \%)$ e energia $(30 \%)$. Porém, após uma oficina de EA com o propósito de desenvolver uma atividade de ecoturismo marinho (PEDRINI et al., 2010b) 
verificou-se um acréscimo significativo na compreensão de que o mar, através de suas microalgas, contribui decisivamente para a respiração dos seres aeróbicos como o homem.

Quanto ao impacto ambiental negativo no ambiente marinho, as pessoas citam, frequentemente, o que está na mídia e no aprendizado escolar, como esgotos (98\%), lixo (86\%) e óleo (80\%) (Souza et al., 2008), porém, sem se dar conta de que sejam eles mesmos os responsáveis pelos impactos citados, como já foi verificado entre turistas em ambientes marinhos (BERCHEZ; CARVALHAL; ROBIM, 2005; MELO; CRISPIM; LIMA, 2005; PEDRINI et al., 2007, 2010b; SILVA; GHILARDI-LOPES, 2012). Concluindo, o mar ou o ambiente marinho é deficientemente conhecido pela população costeira, que o interpreta como um recurso a ser utilizado pela sociedade, mesmo tendo a informação de que esse uso pode trazer prejuízos aos ambientes e organismos marinhos e, em última instância, à própria população humana que depende de seus recursos.

O ecoturismo marinho é uma das possibilidades de se apresentar não só a composição, mas, também, a importância do mar. Hannak (2008), ao estudar a percepção dos praticantes de mergulho numa trilha marinha para snorkellers em praias do Egito, verificou que eles praticam esse tipo de turismo marinho pela busca de contato com a natureza $(96 \%)$ ou em busca de recreação (86\%). Orams (1997), no turismo de observação de cetáceos, identificou que esse público deseja aprender com as atividades turísticas. Ou seja, há sujeitos interessados em atividades turísticas ligadas aos seres marinhos para aprender sobre eles e seu meio. Desse modo, a compreensão sobre a composição e papel do meio marinho para os seres vivos é uma demanda importante como base do conteúdo de uma atividade de ecoturismo marinho.

\section{Material e Métodos}

\section{1.Área Estudada}

O município de Armação de Búzios, no estado do Rio de Janeiro, possui praias de enorme valor estético, sendo uma das cidades mais procuradas pelo turismo de sol e mar e turismo na natureza, no país. No entanto, observa-se que o turismo massificado vem degradando seus atrativos naturais, sendo urgente a necessidade de implantarem-se programas que direcionem as empresas envolvidas e demais atores sociais ao Turismo Sustentável (BARBOSA, 2003). Oigman-Pszczol et al. (2007) identificaram e quantificaram o lixo marinho em dez praias selecionadas da Área de Proteção Ambiental Marinha de Armação dos Búzios. Amostraram 16.000 itens de lixo classificados em sete categorias. A categoria que teve maior abundância local foi o papel, especificamente de cigarros. Atribuíram como fonte desse lixo os turistas que visitam com grande intensidade a área e, ainda, sugerem a hipótese de que o governo municipal não oferece locais para recebimento do lixo dos turistas.

Os potenciais impactos negativos do turismo de cruzeiros marítimos podem ser verificados com os resultados de Castro (2011). Ele registrou que o município de Armação de Búzios recebeu 26 escalas de variados cruzeiros e, respectivamente, 25 mil passageiros na temporada de 1997-1998. Esse montante passou para 223 escalas e com a estimativa de 482 mil passageiros na temporada de 2011-2012. Castro mencionou uma série de inconvenientes dessa atividade que, no momento, não possui uma regulamentação adequada que vise à conservação ambiental local. Pedrini et al. (2011) mencionam os esforços das Secretarias de Meio Ambiente e de Turismo de Armação de Búzios em conjunto com a Secretaria do Ambiente do Estado do Rio de Janeiro para limitar o impacto ambiental negativo do aporte de transatlânticos na região. Uma das conquistas elogiáveis desses três órgãos públicos foi a limitação de acesso ao continente de dois navios por vez ao largo da cidade. 
Levando-se em consideração o cenário exposto anteriormente, não é difícil concluir que existe uma grande demanda, ou até urgência, para a implementação de medidas conservacionistas na área de estudo e, com isso, em 2009 o governo municipal criou a Área de Proteção Ambiental Marinha de Armação de Búzios (APAMAB) que é toda a área marinha do município (Figura 1). No entanto sua implementação ainda não estava plenamente efetuada (PEDRINI et al., 2011). Deve-se chamar a atenção para o fato de que toda a extensão da APAMAB e, especificamente, do Parque Natural dos Corais (PNC) apresente grande potencial e vocação para a implantação de projetos voltados ao ecoturismo marinho em bases sustentáveis, que consiste na atividade socioeconômica mais indicada para a região.

Figura 01 - Localização da Armação de Búzios (esq.) e representação dos limites da APAMAB (dir.)

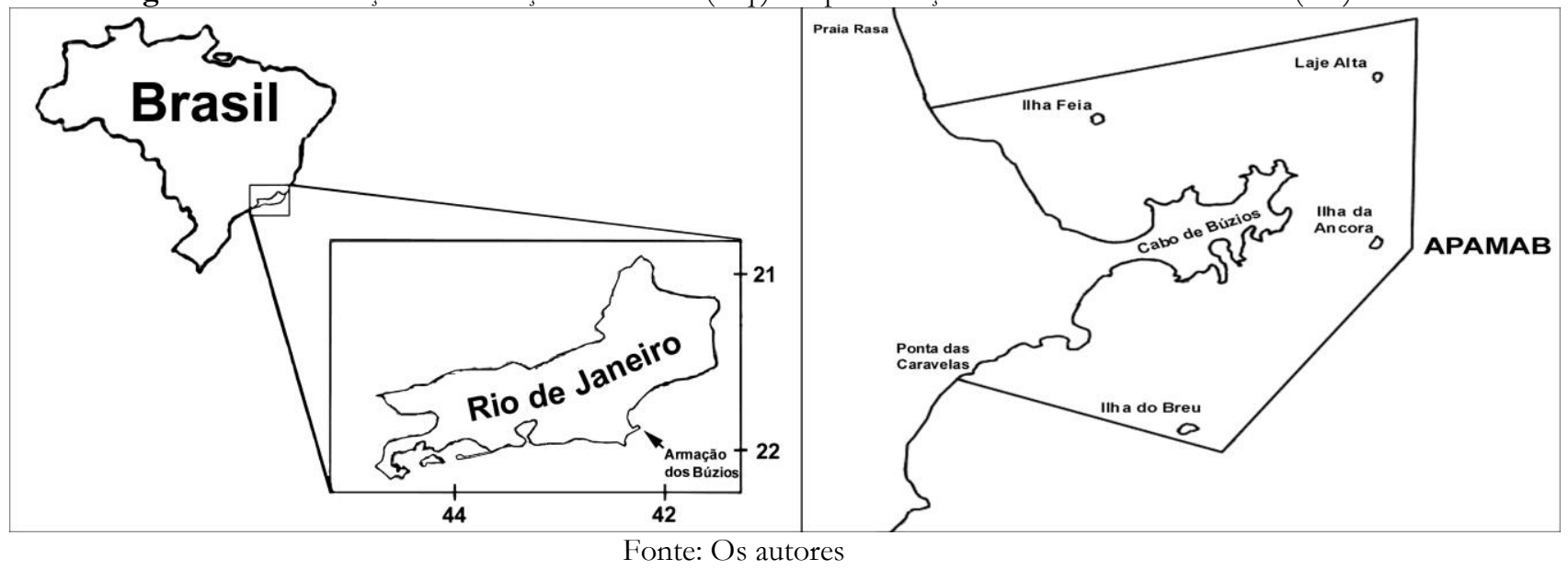

\subsection{Procedimento amostral e metodologia estatística}

Um questionário específico foi enviado por e-mail pelo método da bola de neve (PEDRINI, 2007) a pessoas de perfis variados, que tinham relação com a cidade de Armação de Búzios (p.ex. comerciantes, hoteleiros, moradores locais, professores etc.). A técnica é uma forma de amostra não probabilística utilizada em pesquisas sociais, na qual os participantes iniciais indicam novos participantes, que, por sua vez, indicam outros participantes e assim sucessivamente, até que seja alcançado o objetivo proposto.

O questionário foi também distribuído nas listas das principais redes brasileiras de educação ambiental e meio ambiente. Esse questionário constituiu-se de 16 questões, cinco referentes ao perfil do respondente, seis referentes às opiniões sobre turismo marinho e cinco referentes ao nível de conhecimento sobre o meio ambiente.

Foram idealizadas categorias de análise sobre os construtos conceituais para a percepção do meio ambiente e do meio ambiente marinho (mar) por parte dos respondentes. Essas categorias se traduziram de acordo com critérios específicos para a construção dos indicadores. Para o conceito de meio ambiente tais critérios seguiram, basicamente, a classificação de Reigota (2007) apresentada abaixo, no Quadro 01.

Quadro 01 - Indicadores de caracterização conceitual e descrição do construto meio ambiente

\begin{tabular}{cc}
\hline Indicador & Descrição do indicador \\
\hline $\begin{array}{c}\text { Humanizante } \\
\text { antropocêntrico) }\end{array}$ & Conceito em que o meio envolve essencialmente o uso pelos seres \\
humanos
\end{tabular}




\begin{tabular}{cc}
\hline $\begin{array}{c}\text { Integrador } \\
\text { (globalizante) }\end{array}$ & $\begin{array}{c}\text { Conceito em que o meio envolve a convivência entre todos os seres } \\
\text { vivos e seus ambientes }\end{array}$ \\
\hline Fonte: adaptado de Reigota (2007)
\end{tabular}

A definição do conceito de Ambiente Marinho (AM) foi baseada numa delimitação genérica presente na obra de Tommasi (2008). Consiste em um espaço territorial contendo, basicamente: a) água salgada; b) vegetais (algas e gramas marinhas); c) animais; d) areia/rocha. O Quadro 02 apresenta os indicadores de caracterização conceitual do ambiente marinho. A avaliação dos conceitos expressos pelos respondentes foi feita segundo uma escala em que as classificações (Adequado, Parcialmente Adequado e Inadequado) correspondiam, respectivamente, à presença de 3-4 indicadores, dois indicadores e uma ou nenhuma presença de indicadores acima citados (Fonte: os autores).

Quadro 02 - Indicadores de caracterização conceitual do construto meio ambiente marinho. Escala: Adequado: presença de 3 a 4 indicadores; Parcialmente Adequado: presença de 2 indicadores; Inadequado: 1 ou nenhuma presença de indicador

\begin{tabular}{cc}
\hline $\mathbf{N}^{\mathbf{0}}$ & Indicadores de Caracterização Conceitual \\
\hline 1 & Presença de água salgada \\
\hline 2 & Presença de rochas/ areia \\
\hline 3 & Presença de animais \\
\hline 4 & Presença de algas/vegetais \\
\hline & Fonte: os autores
\end{tabular}

As frequências de respostas referentes ao conceito de ambiente marinho apresentando construtos nas categorias: adequado, parcialmente adequado, inadequado ou não respondido foram avaliadas, além das frequências de respostas referentes ao conceito de meio ambiente nas categorias integrador, naturalizante ou humanizante. Os respondentes foram categorizados quanto à faixa etária, nível de instrução, renda e origem. O teste do Qui-Quadrado (STATISTICA for Windows, 5.1) foi aplicado para avaliar as significâncias das diferenças encontradas.

\section{Resultados}

\subsection{Perfil dos Respondentes}

Os respondentes ao questionário somam um total de 78 indivíduos, com um sutil predomínio do sexo masculino, com 43 homens (55\%) e 35 mulheres (45\%). Os respondentes se apresentavam distribuídos por uma ampla faixa etária (16-60 anos) com predominância entre 41 e 50 anos (28\%), sendo que do total de 78 pessoas, 10 (14,7\%) não forneceram sua idade. O nível de escolaridade dos respondentes variou do ensino fundamental, com seis pessoas $(8,8 \%$ ), ao doutorado, com duas pessoas (2,5\%). Mais da metade dos participantes (53 pessoas - $68 \%$ ) tem pelo menos o nível superior, o que sugere que os respondentes sejam pessoas bem qualificadas quanto à escolaridade. Apesar de possíveis inveracidades quanto à renda declarada, evidenciou-se que grande parte dos respondentes (53\%) tem renda entre $\mathrm{R} \$ 622,00$ e $\mathrm{R} \$ 2.488,00$ (1 - 4 salários minímos), em um total de 73 respondentes quanto a esta informação (Figura 2). 
Figura 02 - Frequências percentuais dos respondentes dos questionários quanto ao sexo (A), classes etárias (B), escolaridade (C) e renda (D).
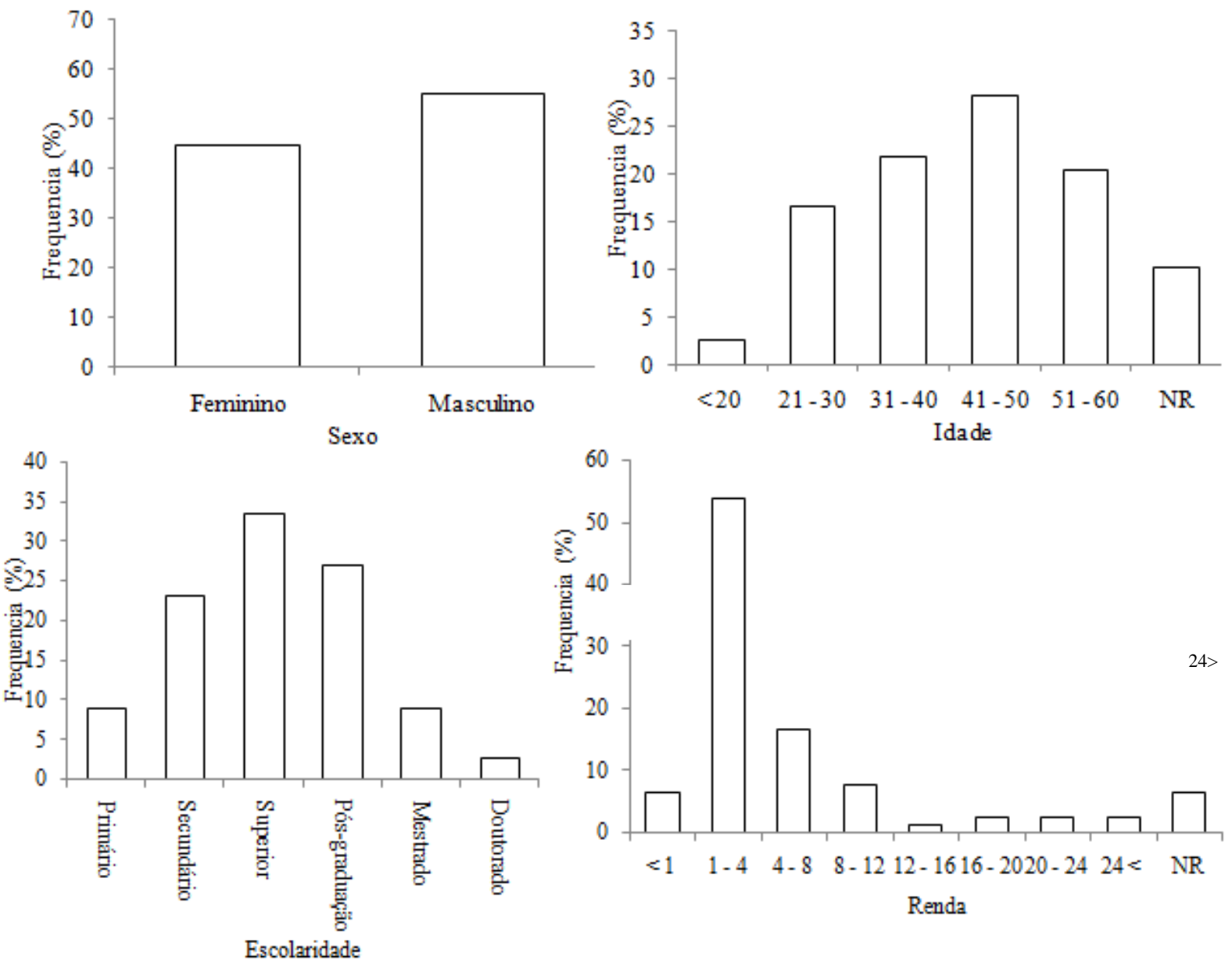

Fonte: os autores

A maioria dos respondentes (80,8\%) reside no estado do Rio do Janeiro e a minoria provém de outras localidades. A maior parte dos respondentes naturais do estado do Rio de Janeiro (52\%) é natural de Búzios e uma parcela significativa $(25,4 \%)$ é da cidade do Rio de Janeiro, demonstrando a superioridade numérica dos residentes em Armação de Búzios. Os respondentes não oriundos do estado do Rio de Janeiro provêm, em sua maior parte, da Argentina, especificamente de Buenos Aires, seguido em menor escala pelo estado de São Paulo. O predomínio de argentinos e fluminenses sobre brasileiros de outros estados evidencia a escolha destes pelo destino buziano (Figura 3).

Evidencia-se uma vasta gama de papéis sociais liderados numericamente pelos moradores $(19,2 \%)$ e banhistas $(14,1 \%)$. Com relação às atividades de lazer, os respondentes demonstram maior interesse em passeios pela cidade de Búzios. Porém, na escala das atividades mais procuradas, o Ecoturismo se encontra em segundo lugar, à frente de atividades consideradas emblemáticas da região como os passeios de escuna. Também foram citadas atividades relacionadas à atrativos históricos e culturais, caminhada, conhecer outras pessoas e esportes aquáticos (Figura 3). 
Figura 03 - Frequência percentual dos respondentes de acordo com a origem (A e B), papel social (C) e atividades de interesse para o lazer na região da Armação de Búzios (D)
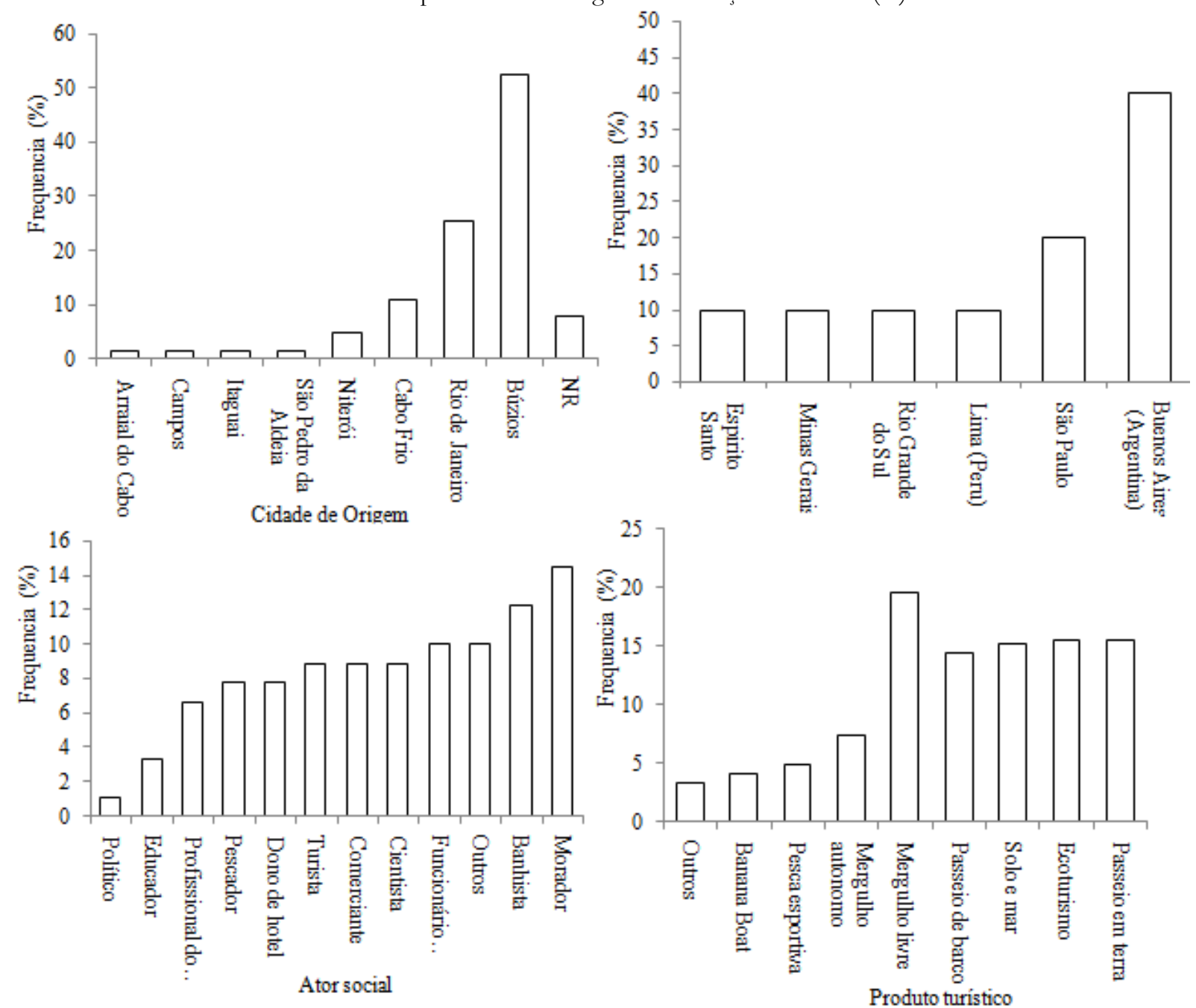

Fonte: os autores

\subsection{Percepção dos Construtos}

\subsubsection{Meio Ambiente}

A análise de conteúdo demonstrou que, quanto ao conceito de meio ambiente, os respondentes apresentaram a concepção integradora como a mais frequente $(53 \%)$, seguida pela concepção naturalizante $(27 \%)$ e a concepção humanizante $(10 \%)$, sendo que $10 \%$ dos respondentes não responderam essa questão (Figura 4). 
Figura 04 - Frequência percentual de respostas sobre o conceito de Meio Ambiente, segundo a concepção expressa pelos respondentes

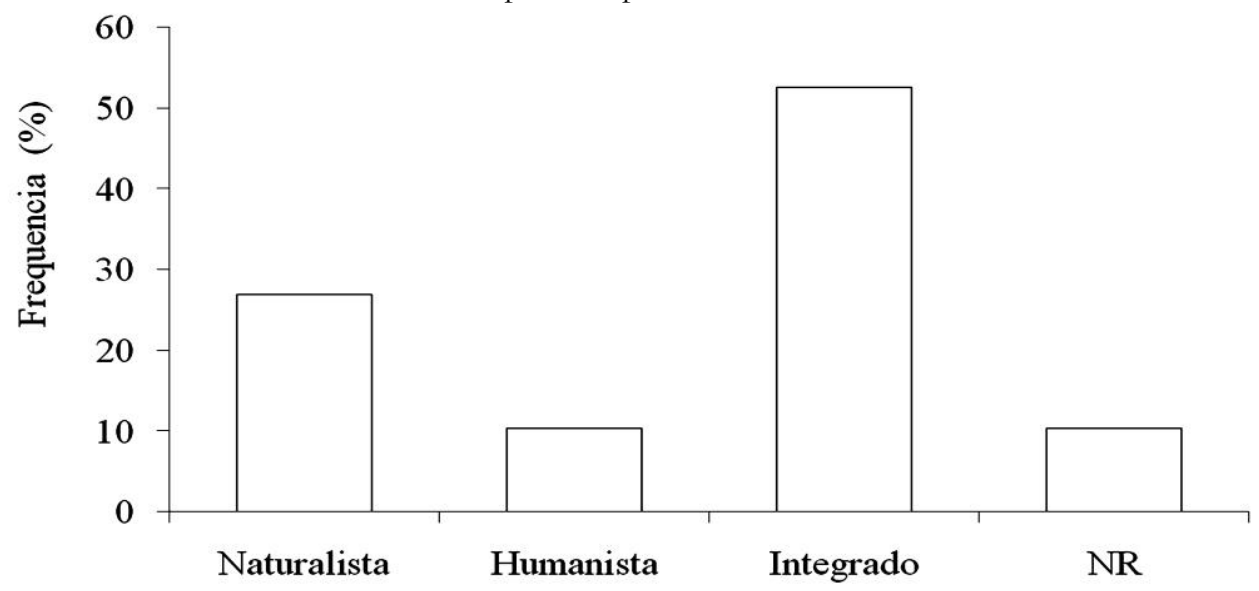

Conceito de meio ambiente

Fonte: os autores

A maioria significativa (Qui-quadrado, $\mathrm{X}^{2}=8,73, p<0,5 \%$ ) dos respondentes que apresentaram o conceito integrador é originária de outras regiões que não a região dos lagos (que inclui Búzios, Cabo Frio e Arraial do Cabo). Também é possível notar que muitos habitantes da região dos lagos apresentam uma concepção naturalista quanto ao conceito de meio ambiente (Figura 5).

Figura 05 - Frequência percentual de respostas sobre o conceito de Meio Ambiente, segundo a categorização empregada e a região de origem dos respondentes

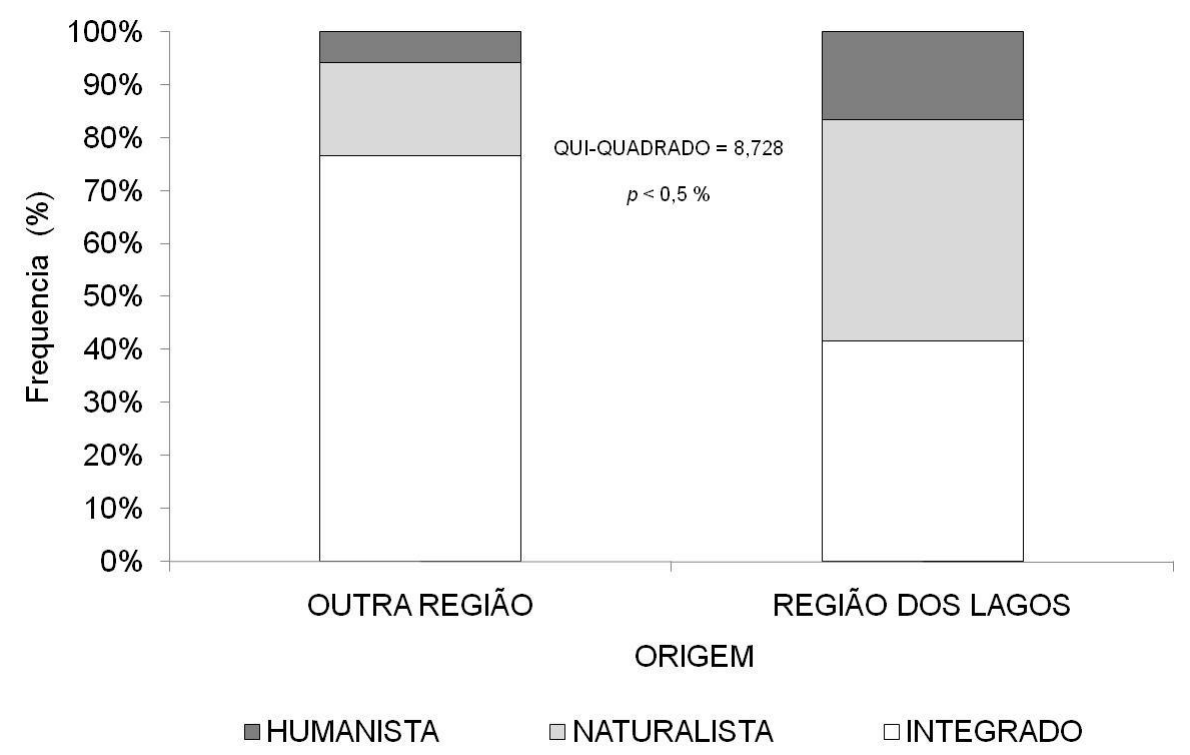

Fonte: os autores

Não foi observada diferença significativa (Qui-quadrado, $\mathrm{X}^{2}=0,811, p>5 \%$ ) para a concepção de meio ambiente entre os sexos. O conceito integrador de meio ambiente foi observado com maior frequência tanto para o sexo masculino (53,8\% dos que responderam) quanto para o sexo feminino (64,5\% dos que responderam) (Figura 6). 
Figura 06 - Frequência percentual de respostas sobre o conceito de Meio Ambiente, segundo a categorização empregada e o sexo dos respondentes

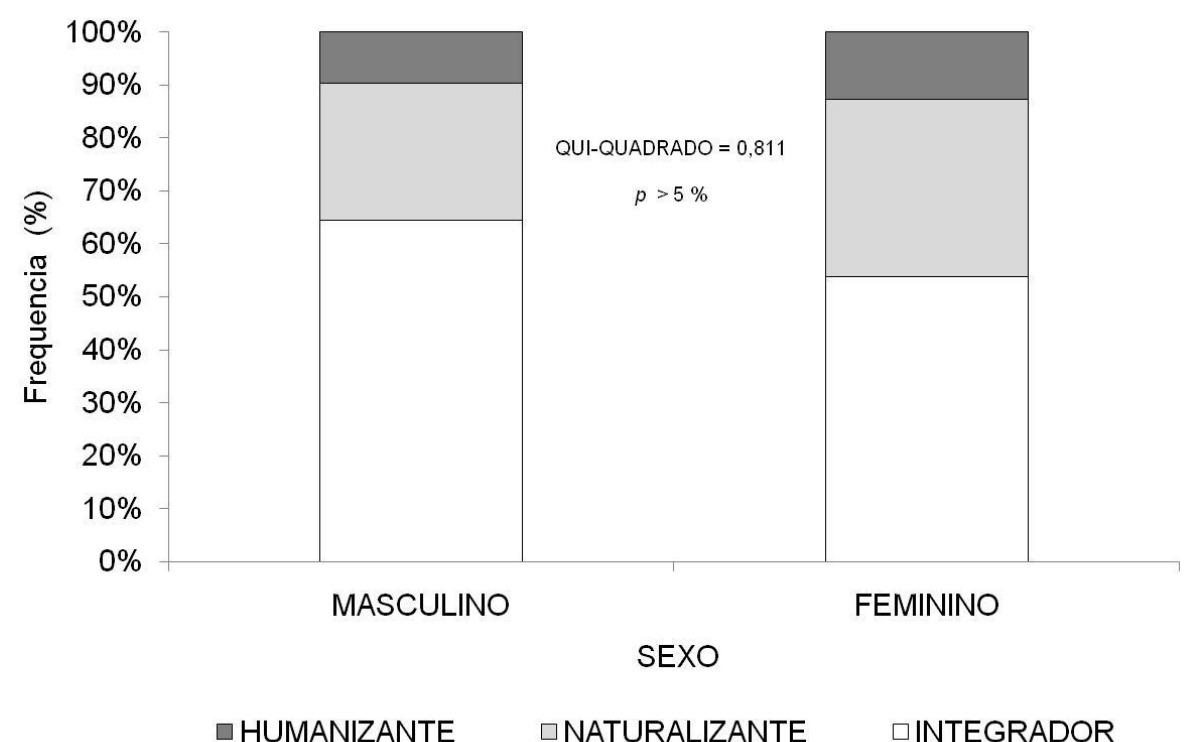

Fonte: os autores

Dessa forma, se levarmos em conta os níveis de significância resultantes dos testes realizados, acima apresentados, observa-se que a região de origem dos respondentes tem maior relevância como fator modelador da visão de meio ambiente, se comparada ao sexo.

\subsubsection{Ambiente Marinho}

Já em relação ao conceito de ambiente marinho, foram observadas $32 \%$ de respostas apresentando a concepção adequada, 40\% como parcialmente adequada e $21 \%$ como inadequada, sendo que ocorreram 6\% de não respondentes (Figura 7).

Figura 07 - Frequência percentual de respostas sobre o conceito de ambiente marinho, segundo a categorização empregada

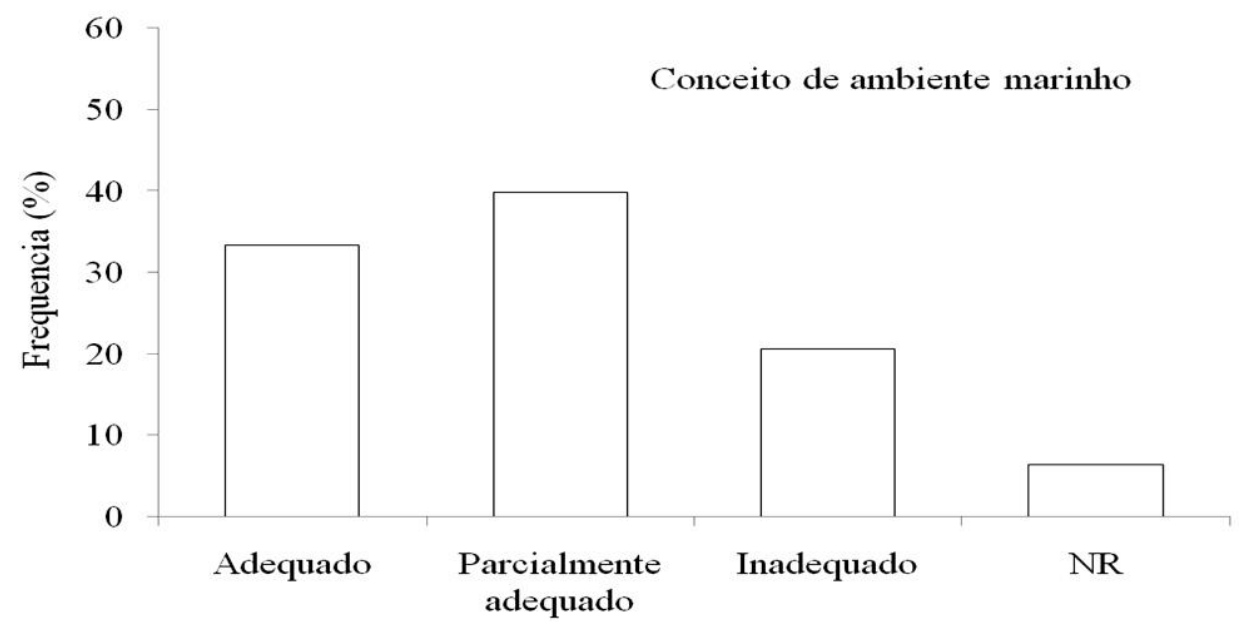

Fonte: os autores

Foram observadas diferenças significativas para a concepção de meio ambiente marinho (Qui-quadrado, $\mathrm{X}^{2}=4,14, p<5 \%$ ) quanto à origem dos respondentes. Os respondentes da 
região dos lagos apresentaram $45 \%$ de frequência de conceitos parcialmente adequados, $30 \%$ de conceitos inadequados e $25 \%$ adequados. Já os respondentes de outras regiões apresentaram $48 \%$ de conceitos adequados, $40 \%$ de conceitos parcialmente adequados e 12\% inadequados (Figura $8)$.

Figura 08 - Frequência percentual de respostas sobre o conceito de ambiente marinho, segundo a categorização empregada e a região de origem dos respondentes

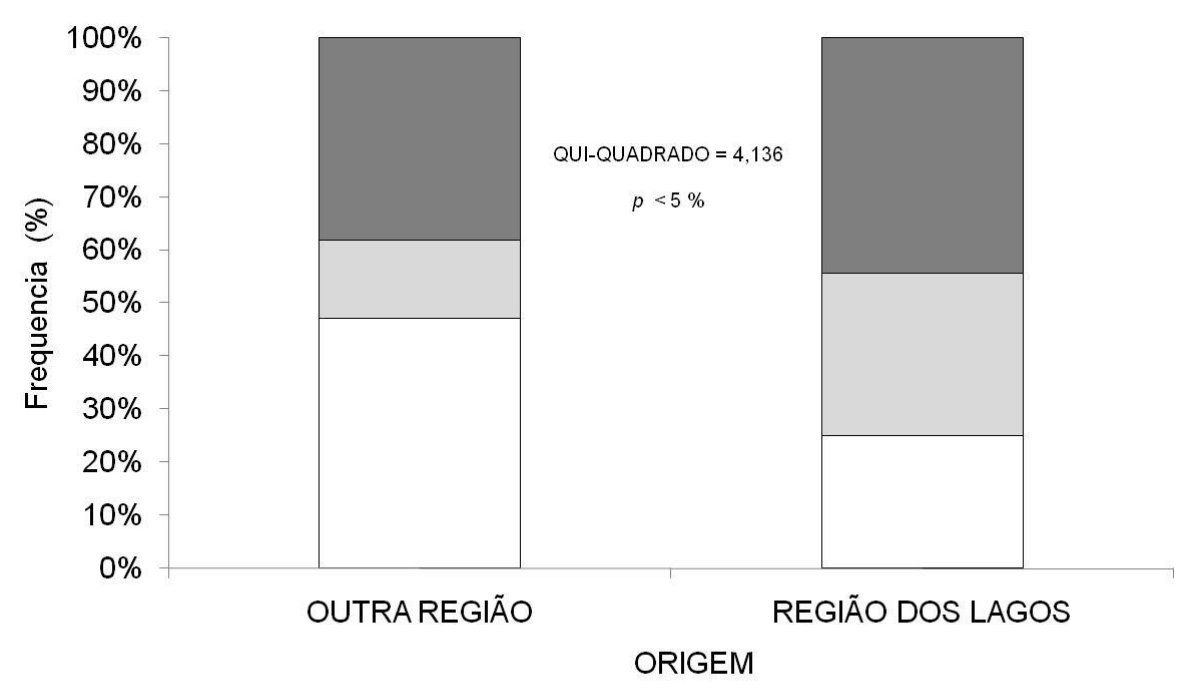

$\square$ PARCIALMENTE ADEQUADO $\square$ INADEQUADO $\square$ ADEQUADO

Fonte: os autores

Foram observadas diferenças significativas (Qui-quadrado, $\mathrm{X}^{2}=7,22, p<1 \%$ ) para $\mathrm{o}$ conceito de meio ambiente marinho entre os sexos, os respondentes do sexo masculino apresentaram $50 \%$ de respostas parcialmente adequadas, 30\% adequadas e $20 \%$ inadequadas; já os do sexo feminino apresentaram $40 \%$ de conceitos adequados, seguido de $30 \%$ de conceitos inadequados e $30 \%$ parcialmente adequados (Figura 9).

Figura 09 - Frequência percentual de respostas sobre o conceito de ambiente marinho segundo a categorização empregada e o sexo dos respondentes

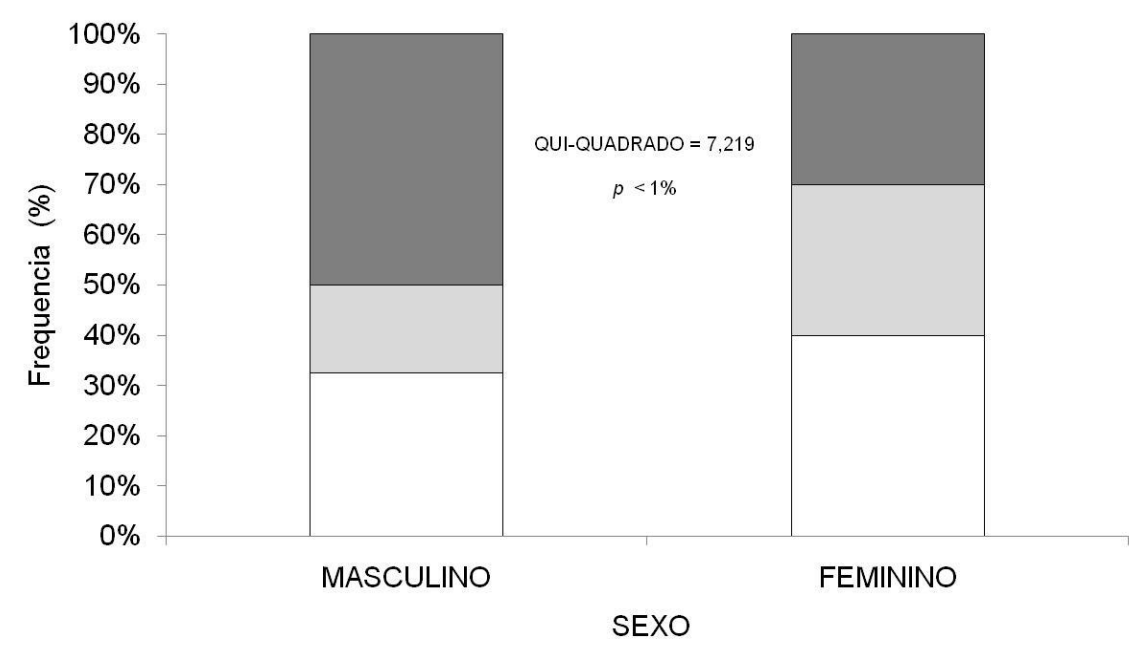

$\square$ PARCIALMENTE ADEQUADO $\square$ INADEQUADO $\square$ ADEQUADO 


\section{Discussão}

Foi possível observar, no presente trabalho, que as visões integradora e naturalista de meio ambiente foram predominantes nos respondentes. Camargo e Branco (2003), ao estudarem o conceito de meio ambiente (MA) de 90 professores de ciências naturais e humanas da cidade de Balneário de Camboriú (estado de Santa Catarina) de escolas públicas e particulares, identificaram uma concepção de meio ambiente com maioria simples de $49 \%$ relativa ao aspecto naturalizante. Porém, a visão integradora chegou perto dessa maioria com $45 \%$. Isso sugere uma visão fragmentada em duas categorias majoritárias; porém, o que fica ressaltado em relação ao presente trabalho é que, em ambos, a visão humanizante foi muito baixa. Essa convergência de resultados, com a baixa porcentagem de respondentes com a visão de que o meio ambiente seria apenas para a satisfação das necessidades humanas pode ser considerado positivo. Martinho e Talamoni (2007) ao estudarem o conceito de MA de crianças através de desenhos, escrita e rodas de conversa encontraram $70 \%$ dos alunos com visão naturalista e $25 \%$ com visão antropocêntrica (humanizante). Apesar de terem envolvido crianças tanto do meio rural como urbano, a maioria absoluta apresentou uma visão naturalista. Pedrini et al. (2010b) encontraram, na sua pesquisa com turistas do Parque Estadual da Ilha Anchieta, no estado de São Paulo, uma expressiva maioria da visão integrada do meio com cerca de $50 \%$ de respostas. A categoria humanizante foi também a de menor proporção, com cerca de $20 \%$. Como visto acima, a maioria dos trabalhos selecionados apresentaram ou uma maioria integradora ou naturalizante, porém sempre com a visão humanizante baixa. Isso sugere que está havendo uma aquisição, quer seja pela mídia ou pelas escolas, de um conceito mais abrangente de MA, em que se nota os seres humanos compartilhando seus recursos e interagindo com outros seres vivos, animais e vegetais. Essa percepção de interdependência socioambiental é o que se deseja. Porém, é importante que sejam feitas mais pesquisas similares para verificar se o que foi encontrado é uma tendência de grande escala ou não.

O fato do conceito de ambiente marinho ou mar ter sido expresso, majoritariamente, de forma parcialmente adequada ou inadequada é preocupante, pois o Parque Natural dos Corais estava sendo planejado para a região. Além disso, a diferença encontrada entre os sexos e a origem dos respondentes também deve ser levada em consideração. $O$ público masculino e feminino percebe o ambiente marinho de maneira ligeiramente diferente, e isso deve ser trabalhado em atividades de EA. Já o fato dos respondentes da região dos lagos ter expressado conceitos inadequados em maior quantidade também deve ser considerado. Esse resultado reforça a conclusão de Oigman-Pczczol et al. (2007) que verificaram que a maioria (52\%) das pessoas confundia coral mole com algas marinhas bentônicas e coral duro com pedras ou esponjas. Desse modo, as pessoas quase nada compreendem sobre o mar. Em outras regiões geográficas brasileiras esse desconhecimento se repete. Docio, Razera e Pinheiro (2009) também encontraram, na Bahia, confusão da população reconhecendo as esponjas marinhas como plantas. Além disso, 18\% dos entrevistados não sabiam que coral era um ser vivo. Pedrini et al. (2010b), numa pesquisa realizada no Parque Estadual da Ilha Anchieta, no estado de São Paulo, verificaram que os turistas que o visitavam desconheciam a contribuição do mar para o planeta Terra. Não sabiam, por exemplo, que na água do mar costeira as microalgas é que exportavam para o ar o oxigênio demandado pelos animais como o homem. De fato, muitos só sabiam que o mar é fundamental apenas para controlar o clima, assunto esse muito disseminado pela mídia. 


\section{Considerações finais}

O perfil do público respondente se apresentou como de pessoas principalmente entre 4150 anos e com qualificação de nível superior, em sua maioria. A maioria era do estado do Rio de Janeiro, sendo maioria absoluta residente da cidade de Armação de Búzios. A maioria recebia, à época, de 1 a 4 salários mínimos, o que sugere uma faixa baixa de ganhos, considerando que o turismo enseja distribuição dos seus benefícios. A maioria dos respondentes apresentou um conceito adequado sobre Meio Ambiente, em que seria o lugar de convivência harmônica entre o meio biótico e abiótico, incluindo o ser humano. Uma minoria afirmou que o meio seria apenas para o ser humano. Quanto ao ambiente marinho, ao contrário, a maioria demonstrou pouco saber sobre o mar. O Parque Natural Municipal dos Corais e a Área de Proteção Ambiental Marinha de Armação dos Búzios estavam sendo implantados, na cidade, enquanto áreas marinhas protegidas. Desse modo, seria importante que houvesse um amplo programa de informação pública e de Educação Ambiental sobre o ambiente marinho da região. Nesse caso, as escolas deveriam ser convocadas para que, no espaço formal, fossem feitas transcrições curriculares, e no espaço não formal fossem desenvolvidos programas de Educação Ambiental, cujas práticas fossem realizadas diretamente nas áreas protegidas do parque. Nesse caso, os alunos teriam mais condição de atuarem na sua conservação como cidadãos e também como monitores ou condutores em atividades de ecoturismo marinho, preservando a memória local e a exuberância da biodiversidade marinha.

\section{Referências}

ALVES, D. (Org.) Olhar perceptivo: percepção, corpo e meio ambiente. Brasília: Ibama, 2010. 112 p.

BARBOSA, K. C. Turismo em Armação dos Búzios (RJ, Brasil): Percepções locais sobre os problemas da cidade e diretrizes prioritárias de apoio a gestão ambiental. 2003. 124 f. Dissertação (Mestrado em Ciência Ambiental), Universidade Federal Fluminense, Niterói. 2003.

BERCHEZ, F.; CARVALHAL, F.; ROBIM, M. J. Underwater interpretative trail -guidance in improve education and decrease ecological damage. International Journal of environment and Sustainable Development, Genebra, v. 4, n.2, p. 128-139, 2005.

BERCHEZ, F.; GHILARDI, N.; ROBIM, M. de J.; PEDRINI, A. de G.; HADEL, V. F.; FLUKIGER, G.; SIMÕES, M.; MAZZARO, R.; KLAUSENER, C.; SANCHES, C.; BESPALEC, P. Projeto trilha Subaquática - Sugestão de diretrizes para a criação de modelos de Educação Ambiental para ecossistemas marinhos. Olam - Ciência e Tecnologia, Rio Claro (SP), v.7, n. 3, p. 181-208, 2007. 1 CD-ROM.

CAMARGO, S.C.G.; BRANCO, J.O. A Educação ambiental na visão dos professores de Ciências Naturais, humanas e linguagem, Balneário Camboriú, SC. In: SIMPÓSIO SULBRASILEIRO DE EDUCAÇÃO AMBIENTAL, 1., ENCONTRO DA REDE SULBRASILEIRA DE EDUCAÇÃ̃O AMBIENTAL, 1., COLÓQUIO DE PESQUISADORES EM EDUCAÇÃO AMBIENTAL DA REGIÃO SUL, 2., 2003, Itajaí- SC. Anais... Itajaí- SC: UNIVALI.

CASTRO, C. B. Cruzeiros de turismo em Búzios: prós e contras. Projeto Coral Vivo Notícias, Rio de Janeiro, v. 17, p. 2, jul/set de 2011.

DOCIO, L.; RAZERA, J. C. C.; PINHEIRO, U.S. Representações Sociais dos Moradores da Baía de Camamu sobre o filo Porífera. Ciência \& Educação, Bauru, v. 15, n. 3, p. 613-629, Out. 2009. 
GARROD, B.; WILSON, J. C.; BRUCE, D. M. Ecoturismo Marino Genuinamente Sostenible en el Área Atlântica de La UE: Guia de Buenas Prácticas. Bristol: University of the Weast of England, 2002. 81 p.

GUIMARÃES, S. T. Dimensões da Percepção e Interpretação do Meio Ambiente: Vislumbres e Sensibilidades das Vivências Na Natureza. Olam - Ciência \& Tecnologia, Rio Claro (SP), v. 4, n.1, p. 46-65, 2004. 1 CD-ROM.

HADEL, V. F. Programa de Visitas ao Centro de Biologia Marinha-USP: o monitor na mediação entre a Academia e o grande público. In: PEDRINI, A. de G. (Org.) Educaşão Ambiental Marinba e Costeira no Brasil. Rio de Janeiro: Eduerj, 2010. p. 93-114.

HANNAK, J. S. A snorkel trail based on reef condition and visitor perception as a management tool for a threatened shallow water reef in Dabab (South Sinai, Egypt). 2008. 53 f. Tese (Magistra der Naturwissenschaften) Universität Wien, Wien 2008.

MARIN, M.; OLIVEIRA, H. T.; COMAR, V. A Educação ambiental num contexto de complexidade do campo teórico da percepção. Interciência, Caracas, v. 28, n. 10, p. 616-619, 2003.

MARTINHO, L. R.; TALAMONI, J. L. B. Representações sobre meio ambiente de alunos da quarta série do ensino fundamental. Ciência \& Educação, Bauru, v. 13, n. 1, p. 1-13, 2007.

MELO, R. S; CRISPIM, M.C.; LIMA, E.R.V. O turismo em ambientes recifais: em busca da transição para a sustentabilidade. Caderno Virtual de Turismo, v. 5, n. 4, p. 34-42, 2005. Disponível em: <http://www.ivt.coppe.ufri.br/caderno/ojs/viewarticle.php?id=105>. Acesso em: 2 Fev. 2012.

MINISTÉRIO DO MEIO AMBIENTE. Panorama da Conservação dos Ecossistemas Costeiros e Marinhos no Brasil. Brasília: Secretaria de Biodiversidade, 2010. 148 p.

MOSCOVICI, S. Representações sociais: investigações em psicologia social. 5. ed. Petrópolis: Vozes, 2007.

OIGMAN-PSZCZOL, S.S.; OLIVEIRA, A.E.S.; CREED, J. C. Perceptions of coral in coastal tourist town in Brazil. Coral Reefs, Den Burg, n. 26, p .667-670, 2007.

ORAMS, M. B. The Effectiveness of Environmental Education: Can We Turn Tourists into "Greenies"? Progress in Tourism and Hospitality Research, Malden, v. 3, p. 295-306, 1997.

PACHECO, E.; SILVA, H.P. Compromissos epistemológicos do conceito de percepção ambiental. In: SEMINÁRIO DE ÁREAS PROTEGIDAS E INCLUSÃO SOCIAL, 1, 2006, Rio de Janeiro. Anais... Rio de Janeiro: UFRJ, 2006. 1 CD-ROM.

PEDRINI, A. G. Um caminho das pedras. In: PEDRINI, A. G. (Org.) Metodologias em Educação Ambiental. Petrópolis: Vozes, 2007. p.23-51.

PEDRINI, A.G.; ANDRADE-COSTA, E.; GHILARDI, N.P. Percepção ambiental de crianças e préadolescentes em vulnerabilidade social para projetos de educação ambiental. Ciência \& Educação, Bauru, v. 16, n.1, p. 163-179, 2010a.

PEDRINI, A.G.; MESSAS, T.; PEREIRA, E.F.; GHILARDI, N.P.; BERCHEZ, F. Educação ambiental pelo ecoturismo numa trilha marinha no Parque Estadual da Ilha Anchieta, Ubatuba, São Paulo. Revista Brasileira de Ecoturismo, São Paulo, v.3, n.3, p. 428-459, 2010b. Disponível em:http://www.sbecotur.org.br/rbecotur/seer/index.php/ecoturismo/article/view/97/50; Acesso em: 1 jul. 2011. 
PEDRINI, A.G.; BROTTO, D.S.; LOPES, M.C.; MESSAS, T. Gestão de Áreas Protegidas com Educação Ambiental Emancipatória pelo Ecoturismo Marinho: A Proposta do Projeto Ecoturismar. Olam Ciencia \& Tecnologia, Rio Claro (SP), n. 3, especial, p. 6-81, set. 2011. Disponível em: $\leq$ http://www.periodicos.rc.biblioteca.unesp.br/index.php/olam/article/view/4967>. Acesso em: 1 ago. 2011.

PEDRINI, A.G.; COSTA, C.; NEWTON, T.; MANESCHY, F.S.; SILVA, V.G.; BERCHEZ, F.; SPELTA, L.; GHILARD I, N.P.; ROBIM, M.J. Efeitos ambientais da visitação turística em áreas protegidas marinhas: estudo de caso na Piscina Natural Marinha, Parque Estadual da Ilha Anchieta, Ubatuba, São Paulo, Brasil. Olam - Ciência \& Tecnologia, Rio Claro (SP), v. 7, n. 1, p. 678-696, 2007. 1 CDROM.

PRATES, A.P.L.; DUARTE, A.L.M.; FERREIRA, B.P.; GEORGI, C. LOIOLA, L.; HAZIN, M.C.; REINHART, MH. PEREIRA, P. M. Conduta consciente em ambientes recifais. Brasília: Ministério do Meio Ambiente, 2007. 28 p.

REIGOTA, M. Meio ambiente e representação social. 7 ed. São Paulo: Cortez, 2007.

SALES, E.J.CG. ANTONIO FILHO, F. D. Turismo e a problemática da inclusão/exclusão socioespacial: um estudo exploratório em Armação de Búzios - RJ. In: SIMPÓSIO DE PÓS-GRADUAÇÃO EM GEOGRAFIA DO ESTADO DO SÃO PAULO (SIMPGEO), 1, 2008, Rio Claro. Anais... Rio Claro: UNESP, 2008. p. 1122-1140.

SILVA, J.N.; GHILARDI-LOPES, N.P. Indicators of the impacts of tourism on hard-bottom benthic communities of Ilha do Cardoso State Park (Cananéia) and Sonho Beach (Itanhaém), two southern coastal áreas of São Paulo State (Brasil). Ocean and Coastal Management, v. 58, p.1-8, 2012.

SMYTHE, J.C. Environment and Education: a view of a changing scene. Environment Education Research, v. 1, n. 1, p. 1-20, 1995.

SOUSA, A.S.; NUNES, J.L.S.; FERREIRA, D.M.R.; ARAUJO, L.N.C.; MORAIS, E.C. Concepção dos Alunos de Ensino Fundamental e Médio de Escolas Públicas de São Luis sobre a Importância dos Oceanos e seus Fenômenos. In: CONGRESSO BRASILEIRO DE OCEANOGRAFIA (CBO), 3, 2008, Fortaleza. Anais... Fortaleza: Associação Brasileira de Oceanografia, 2008. 1 CD-ROM.

TOMMASI, L. R. Meio Ambiente e Oceanos. São Paulo: SENAC, 2008, 236 p.

TUAN, Y. Topofilia: um estudo da percepção, atitudes e valores do meio ambiente. São Paulo: Difel, 1980.

VASCONCELOS, F. A. L.; AMARAL, F. D.; STEINER, A. Q. Students' view of reef environments in the metropolitan area of Recife, Pernambuco state, Brazil. Arquivos de Ciências do Mar, Fortaleza, v. 41, n. 1, p. 104-112 2008.

WHYTE, A. V. T. Guidelines for Field Studies in Environmental Perception. MAB Technical Notes, Paris, v. $5,1977$.

\section{Agradecimentos}

À Mariana Portilho e Jessica Siviero pela ajuda na alimentação de parte da planilha dos dados e sua análise preliminar. A Beatriz Martins, da Pousada Ville La Plage de Armação de Búzios. À Adriana Saad, Ex-Secretária de Meio Ambiente e Pesca, Ex-Secretário Cristiano Marques, Secretário de Turismo, e Ex-Secretário Rodolfo Lyrio, Secretário de Ordem Pública, os três, da 
Prefeitura de Armação de Búzios, estado do Rio de Janeiro. À Rosana pelo seu apoio pessoal. Aos três revisores da revista pelo aperfeiçoamento desse texto.

Artigo submetido em 03/02/2013

Artigo aprovado em 24/10/2013 